Research Article

\title{
Analysis of Construction Auctions Data in Slovak Public Procurement
}

\author{
Tomáš Hanák $\mathbb{D}^{1}$ and Carles Serrat ${ }^{2}$ \\ ${ }^{1}$ Brno University of Technology, Faculty of Civil Engineering, Brno 635 00, Czech Republic \\ ${ }^{2}$ Universitat Politècnica de Catalunya-Barcelona TECH, Department of Mathematics, IEMAE-EPSEB, Barcelona 08028, Spain \\ Correspondence should be addressed to Tomáš Hanák; hanak.t@fce.vutbr.cz
}

Received 30 May 2018; Revised 14 September 2018; Accepted 8 November 2018; Published 3 December 2018

Academic Editor: M. Shahria Alam

Copyright (C 2018 Tomáš Hanák and Carles Serrat. This is an open access article distributed under the Creative Commons Attribution License, which permits unrestricted use, distribution, and reproduction in any medium, provided the original work is properly cited.

\begin{abstract}
The requirement for efficient public spending leads contracting authorities to use electronic reverse auctions (e-RA), a tool that allows achieving financial savings. In this study, we aim to explore the relationships between the different acting e-RA variables and to check for predictive models in order to infer on the savings amount in construction public procurement. Data on real construction auctions in Slovakia were statistically analysed by means of graphics tools, multiple regression analysis, test, and statistics for measuring the association between categorical variables. The results revealed that one should take the type of contract into account when considering the use of e-RA. This research provides several implications for purchasing practitioners in the area of construction procurement, especially with regard to the level of competition in the auction and estimation of savings potential. Presented findings aid managerial decision-making process of e-RA adoption. At the end, recommended future research directions in the investigated area are outlined.
\end{abstract}

\section{Introduction}

Construction projects typically have a high degree of complexity, they are difficult to manage [1], and they are characterized by the high number of stakeholders involved. Therefore, proper attention should be paid to all particular project phases and the individual activities carried out during them. This paper focuses on one particular project phase, that of procurement, which is extremely important from the client's perspective, because selecting a capable contractor increases the probability that the main project goals [2, 3]-cost, time, and quality-will be achieved. However, time [4] and cost overruns are common for construction projects and often the former is followed by the latter $[5,6]$. Furthermore, due to the long-term nature of construction activity, changes in the price of materials and costs can be expected and should be taken into account in tender documentation because it is important for the investor to know the final cost of the investment [7].
Construction transactions can be even more risky than others due to their specific nature: it is quite often the case that the partners (client and contractor) do not know each other [8] and that the relationship between them is on a onetime and short-term basis, especially in the area of public procurement.

During the procurement phase, clients should prepare the tender documentation, invite prospective contractors to submit their bids, check the compliance with the qualification prerequisites, evaluate the bids submitted, and award the contract to the winning supplier. Effective negotiation on price as well as other evaluation criteria is important in order to ensure that the client gets the best value for money. For this reason, supporting electronic reverse auctions (e-RA) should be considered. In public procurement, according to the Directive 2014/24/EU on public procurement [9], buyers (i.e., contracting authorities) may use electronic auctions.

Positive outcomes of construction projects, no matter whether they are supported by e-RA or not, can be expected 
only if the necessary requirement of detailed preparation is met. From this perspective, decision-support systems are very helpful [10] and e-RA can be considered as playing a supporting role in achieving project effectiveness and efficiency.

In this study, data on real construction auctions are processed. In this context, construction tenders are understood as tenders that generally relate to the construction sector, i.e., the execution of construction works, delivery of services relating to construction such as maintenance or inspection, delivery of project documentation, and so on.

\subsection{Problem Statement, Objectives, and Structure of the Paper.} It is clear from the literature that there is little quantitative knowledge on the modelling of the relative savings variable. At the same time, however, it is strongly convenient for the clients to have an idea about the amount of the expected relative savings derived from the bidding competition. This paper's main objective and research contribution is to address this problem with a predictive perspective by examining the relationships between the different variables acting in e-RA in the framework of public procurement in Slovakia, as well as by establishing predictive models to infer the amount of savings. To achieve this general aim and to overcome the problem, we will structure the paper according to four specific objectives: (a) to evaluate whether the type of tender is associated with the number of bidders, i.e., with the competitiveness possibilities, (b) to measure the dependency structure among the acting variables, (c) to select predictive variables and the corresponding statistical model for the amount of relative savings, and (d) to estimate the proportion of tenders using the lowest bid price as an evaluation method in the auction, in comparison with other countries in the same geographical area.

The paper is organized as follows. Section 2 provides background relating to e-RA and focuses on related drivers and barriers with regard to construction tenders. Section 3 presents the motivating dataset that will be used across the work. The main statistical research and findings based on the evaluation of quantitative data and related discussion on the results are provided in Section 4. The final section presents the main conclusions and research implications, addresses limitations of the research, and outlines future research directions in the corresponding field of study.

\section{State of the Art}

Clients are motivated to adopt e-RA as they are associated mainly with financial savings [11] and enhanced transparency of the purchasing process [12]. The high significance of these two benefits is confirmed e.g., by an empirical study analysing e-RA users' attitudes in the Czech Republic and Slovakia [13]. Despite the fact that e-RA provide several benefits, the overall rate of adoption is very small, as documented e.g., through the example of Portugal [14]. Although the first-mentioned benefit, financial savings, is reflected only on the side of clients, increased transparency makes e-RA desirable for contractors as well. Muylle and
Standaert [15] revealed that use of procedural fairness in e-RA is positively related to relationship quality. Financial savings can be expected if a sufficient level of competition exists in the tender [16]. A number of studies have assessed the conditions of competition using various indicators, e.g., concentration and inequality [17]. Ye et al. [18] define the project level competition intensity measurement as the extent to which competition happens in a pool of contractors who are bidding for common construction works. Wu and Kersten [19] found out that more efficient and balanced contracts between a buyer and a supplier can be better reached by negotiations than auctions. An interesting finding on the interaction between competition and corruption has been brought by Celentani and Ganuza [20]. They emphasised that more competition may imply higher corruption in certain markets; however, that does not necessarily imply that more competition is undesirable.

From the perspective of e-RA, the level of competition is reflected by the number of suppliers who have submitted their bids. It is usually assumed that four contractors participating in an auction already create the conditions for a successful financial outcome of the auction [21]. The number of bidders is dependent on various factors, not just on the expected value of the contract. Simulation of Schmidt [22] based on game theory has proved that higher transaction costs (such as study of project documentation or bid processing) cause a lower number of bids submitted. Costs of placing the bid cannot be omitted especially in the case of complicated procurement auctions [23].

It is worth noting that the spectrum of construction tenders is very wide (schools, buildings, roads, water/sewage systems, etc.) and together with different market conditions, these differences may affect the amount of competition among contractors. The interaction of supply and demand and the effect of business cycles (economic crises vs. periods of prosperity) affect the amount of contractors' markups [24] as well as the amount of financial savings achieved by clients. Buyers in construction industry can use the level of construction demand as an indicator for timing the tender call [25]. On the example of the Czech Republic, it has been shown that the amount of relative savings achieved in tenders for the performance of works on schools is more dependent on the type of the tender when compared, e.g., to transport infrastructure tenders [26]. Therefore, the type of construction contract may also significantly affect e-RA outcomes.

The implementation of e-RA in construction is hindered by the fact that some contractors are not willing to participate in such auctions [27]. The problem does not involve only e-RA; the construction industry is known for late adoption of IT in general. For example, the study of Zunk et al. [28] has shown that rates of e-procurement adoption in the Austrian construction industry are low and that a significant part of respondents have poor knowledge about e-procurement. Therefore, clients have to seek an optimal balance between the qualification prerequisites and number of participating contractors. More specifically, it is crucial to ensure that only capable contractors submit bids, but at the same time, the qualification prerequisites cannot be so strict 
as to hinder participation of a sufficient number of bidders to facilitate effective price negotiation in e-RA. In this relation, Tkáč et al. [29] have published a study showing 12 reasons why construction companies decline to prepare a proposal for their potential clients, and Leśniak and Plebankiewicz [30] have identified (1) type of the work, (2) experience in similar project, and (3) contractual terms to be the top three most vital factors influencing the bid/no bid decision of contractors. Taking this into account, it is important to estimate individual bidder participation correctly [31].

It is also important to mention that e-RA are not suitable for all types of works. In this context, Directive 2014/24/EU on public procurement [9] in Article 35 notes that "Certain public service contracts and certain public works contracts having as their subject-matter intellectual performances, such as the design of works, which cannot be ranked using automatic evaluation methods, shall not be the object of electronic auctions."

From an ethical perspective, e-RA may also lead to the submission of abnormally low bids [32] as well as delivery of poor-quality products and services. In this relation, Ahmed et al. [33] have used a game theory approach to demonstrate that the majority of contractors suffer from the winner's curse (i.e., winning bidder who have submitted the underestimated bid is selected to perform the project) in different bidding environments. It is difficult for clients to detect abnormally low bid prices as there is no universal definition of abnormality [34]. Different mathematical approaches are used in individual countries, and in some countries, the definition is so vague that no formula is prescribed. The most common systems to detect abnormally in low bid price are arithmetic systems measuring the deviation of a particular bid from the average of all bids submitted [35]. Therefore, specific actions should be taken in this area in order to facilitate the process and detect abnormally low bids [36]. Auctions are also prone to other types of unethical behaviours such as a collusion of suppliers $[37,38]$ or awarding contracts more often to incumbents [39]. The academic literature also notes the problem of a potential drop in quality. Love and $\mathrm{Li}$ [40] claim that poorquality delivery has become an endemic trait of public sector procurement in construction. A detailed description of the required quality followed by adequate prequalification of contractors therefore represents a crucial condition for successful implementation of e-RA [41]. Furthermore, a sufficient level of detail and specifications prevent the occurrence of construction delays, adding to the need for highquality documentation [42]. It should also be noted that unclear tender documents may result in queries, clarifications, or even not submitting a bid at all [43].

Quality e-RA systems support the evaluation of bids by using multicriteria. Despite the fact that awarding the contract on the basis of the lowest bid price is preferred in certain countries, such as the Czech Republic and Poland [44], the most economically advantageous tender can also be supported by e-RA. Ballesteros et al. [35] concluded that reaching the best combination between economic score formulas and abnormally low bid criteria is a challenge and requires further research. For structures, the investor should take into account life-cycle costs [45], i.e., not only costs of the construction works themselves, but also the future operation, maintenance, and demolition costs that affect the effectiveness of any investment [46]. With respect to legal conditions, environmental criteria can also be considered, as applicable, e.g., for transport infrastructure projects [47]. Beyond those yet listed, other meaningful criteria may be applied, such as the duration of construction works (important in the event that they restricts or interrupts operation, e.g., in hospitals and schools) or the duration of warranty. Application of multiply awarding factors such as price and time is also desirable for transport infrastructure projects. For example, Lewis and Bajari [48] proposed a model for giving incentives to contractors to earlier project completion with the aim to reduce costly commuter delays. Using quality as the evaluation criterion is questionable since construction contracts often do not enable variable quality of performance when the individual materials and technological procedures are predetermined. Generally, it is necessary to pay proper attention to choosing the right method of awarding public tenders, as recommended in [49].

Recent study on e-RA [50] has revealed that the use of auctions in construction procurement should also be considered from the perspective of postauction effects within the whole construction project life cycle such as operation and maintenance costs, supervision on the site, or amount/value of additional works. In this relation, engagement of facilities management in the design stage through BIM represents a good presumption for effective monitoring of the building/ structure during and after its completion [51].

According to authors' knowledge, studies on the analysis of the interaction between variables such as number of bidders, best bid before auction, number of changes, and achieved relative saving with a predictive focus have not been conducted yet. Research into this modelling approach is needed in order to estimate the effect of the bidding variables on the resulting saving amounts and to design proper strategies. This is the knowledge gap that this paper aims to overcome.

\section{Slovak e-RA Motivating Dataset}

3.1. Description of Study Area and Current e-RA Regulations. Slovakia is a small country that has experienced transformation of the economy after 1989 and became an independent country in 1993. In 2016, the volume of construction public tenders announced was approximately 1,948 million EUR corresponding to the number of 2,930 contracts [52]. Share of construction in total GDP was estimated at $7.1 \%$ in 2016 [53] and generally growing trend in construction is documented, e.g., by increasing capacity utilization of companies [52]. Basic data on the area under study are presented in Table 1.

In Slovakia, the legislation governing public procurement has been very progressive from an e-RA perspective. From as early as 2011, it has been compulsory to use e-RA for above-threshold and below-threshold public tenders [55]. However, in relation to public works tenders, the Office for Public Procurement [56] decided that the use of auctions 
TABLE 1: Characteristics of study area.

\begin{tabular}{lc}
\hline Indicator & Value \\
\hline Population $(2017)^{*}$ & $5,441,899$ \\
GDP growth $(2016)^{*}$ & $3.3 \%$ \\
Unemployment $(2016)^{*}$ & $9.7 \%$ \\
Inflation rate $(\mathrm{Q} 4 / 2016)^{*}$ & $-0.1 \%$ \\
Average nominal month wage $(2016)^{*}$ & $912 \mathrm{EUR}$ \\
Volume of construction public & 1,948 \\
tenders announced $(2016)^{* *}$ & million \\
\hline
\end{tabular}

${ }^{*}$ Statistical Office of the Slovak Republic, official website [54]; ${ }^{* *} \mathrm{CEEC}$ Research [52].

is mandatory only when it is possible to specify the technical requirements relating to the subject matter, while in other cases, there is no obligation. The Office justified the abovementioned decision by concerns of lowering prices at the expense of quality and the ability of the tender winners to complete the projects according to specifications. There were concerns about the quality with regard to services as well. Since 2014, the requirement to use e-RA has been limited only to the supply of goods that are commonly available on the market (Slovak Republic, Act no. 25/2006 Coll., as amended on 27.2.2014 [57]).

3.2. Dataset on Construction Auctions. For the purpose of this study, data on e-RA were provided by one of the leading e-RA system operators in Slovakia. In order to protect the confidentiality of the data, the dataset was provided anonymized, i.e., it was not possible to ascertain a name of buyer, but it was possible to determine the subject of the purchase. The data represent information on real completed e-RA public tenders relating to construction procurement in Slovakia within 2013-2016 period. A price-setting mechanism for these auctions is a first-price auction, i.e., what you bid is what you pay. For these e-RA, the bidding round is automatically prolonged if any of the suppliers bids shortly before its end (such measure gives other suppliers enough time to respond to this last bid). A total of 170 records were obtained for the purpose of this research. For each e-RA record, it was required that the following detailed information be available: name of the tender, number of applicants who registered in the particular auction, number of applicants who submitted bids (i.e., the number of bidders), expected value of the contract in EUR, best bid before the competition round of the auction in EUR (BBA), winning bid after auction in EUR (i.e., award price, AWP), number of bid changes during the auction, and type of evaluation method used. To evaluate the amount of achieved relative savings (ARSs), the following equation was used:

$$
\text { ARS }=\left(1-\frac{\mathrm{AWP}}{\mathrm{BBA}}\right) \times 100 \text {, }
$$

where BBA represents the value of the best bid price (i.e., the bid with the lowest price) that was submitted by suppliers before the competition round of the auction. Such bids can also be called "initial bids." Each supplier is obliged to submit a complete bid in advance of the competition round. The buyer checks whether the bids are complete and if qualification prerequisites are fulfilled.

\section{Analysis, Results, and Discussion}

4.1. Introduction and Acting Variables. To tackle with the objectives of the paper introduced in Section 1, the motivating dataset in the previous section was statistically analysed. For the computational methodologies, the statistical software Minitab, release 17 [58], was used. The specific statistical tools and methods, like histograms, scatterplots, correlation analysis, multiple regression analysis, chi-square test of independence, and statistics for measuring the association between categorical variables as well as statistics for examining relationships between selected e-RA variables can be found in the study of Montgomery and Runger [59].

In order to allow a more detailed investigation, the records were categorized according to the type and usual nature of the public tender, by defining a type of contract variable (TOC). The following four categories were determined: buildings (BUI, e.g., repairs, replacement of windows, and performing additional thermal insulation), communications (COM, e.g., roads, parking places, and pavements), construction projects and maintenance (PRM, e.g., project documentation, energy audit, cleaning of sewer shafts, and maintenance of the cooling system), and "other" $(\mathrm{OTH})$ category of tenders that did not belong to any of the aforementioned categories. A summary of the variables is presented in Table 2 .

4.2. Preprocessing and Final Dataset. In order to avoid a potential bias on the inferences and conclusions due to the presence of outliers in the dataset, we proceed to remove those records that were outliers in a minimum of two variables. Records were identified as an outlier by using the boxplot-and-whiskers technique. Two debugging steps were needed. Seven records were identified in the first debug and two in the second one. As a result, the final debugged sample, for further processing analyses in this research, was made of 161 e-RA records.

4.3. Descriptive Analysis of the Sample. Sample size of the collected dataset is 161 , and data correspond to records (statistical subjects) on real individual tenders relating to the construction supported by e-RA. Table 3 displays the distribution and percentages of the sample in each category according to the type of the contract and the type of the evaluation method used by the tender. We can observe that the most common type of public contracts were BUI, this category represents $43.5 \%$ of the sample, followed by $22.4 \%$, $20.5 \%$, and $13.6 \%$ for COM, PRM, and OTH, respectively. It is also obvious that the majority of the tenders use the lowest bid price as an evaluation method for solving the auction.

When computing the two-ways table of contingency TOC-TEM, despite the few number of records with TEM = multicriteria, a different distribution pattern of TOC is noticeable within this category, in the sense that the majority of the contracts correspond to $\mathrm{OTH}$, different from BUI in the global sample and also in the TEM = lowest bid price subsample. This result sounds natural when we consider the 
TABle 2: Characteristics (name, description, type, and values) of the variables in the construction auctions dataset.

\begin{tabular}{lccc}
\hline Name & Description & Type & Values/range \\
\hline ID & Identification code & Textual & $1-170$ \\
TOC & Type of contract & Categorical & BUI, COM, OTH, PRM \\
TEM & Type of evaluation method & Categorical & Lowest bid price, multicriteria \\
NOB & Number of bidders & Ordinal & $1-9$ \\
BBA & Best bid before auction & Continuous & $31-634,000 €$ \\
CHA & Number of changes during the auction & Ordinal & $0-1,251$ \\
ARS & Achieved relative saving & Continuous & $0.0-67.8 \%$ \\
\hline
\end{tabular}

TABLE 3: Frequency tables for the categorical variables TOC (type of contract) and TEM (type of evaluation method).

\begin{tabular}{lcc}
\hline Variable & Category & Number of e-RA (\%) \\
\hline \multirow{4}{*}{ TOC } & BUI & $70(43.5)$ \\
& COM & $36(22.4)$ \\
& OTH & $22(13.6)$ \\
\multirow{2}{*}{ TEM } & PRM & $33(20.5)$ \\
\hline
\end{tabular}

variety of projects included in the category $\mathrm{OTH}$, which may require different evaluation methods than the lowest price.

Concerning quantitative variables $\mathrm{NOB}, \mathrm{BBA}, \mathrm{CHA}$, and ARS, the respective mean profile is shown by auctions with 3-4 (3.74) bidders, with a best bid price before auction about $30,000 €(30,015 €)$, that after experimenting about 40 changes during the auction, 42.8 gets relatives saving about $14.0 \%$. However, the distribution of the data in each one of these variable is really asymmetric. Figure 1 illustrates different graphical outputs for these distributions. It is interesting to note (a) the distribution of number of bidders is clearly unimodal, with mode equal to 3 ; however, the distribution is different across the categories of types of contract, (b) despite the debugging outliers' process, variables best bid before auction and number of changes during the auction present a long right tail with potential influencing data, and (c) variables of number of changes and achieved relative savings are zero-inflated in the sense of containing structural zeros corresponding (in part) to those records with the number of bidders equal to 1 that makes not necessary neither introducing changes nor reducing the initial bidding price (in particular, $54.6 \%$ of the auctions with no changes and $31.0 \%$ of the auctions with no savings correspond to auctions with a single bidder, i.e., with no competition).

4.4. Competition in Construction Auctions. As it is argued that strong competition is a necessary condition for achieving the favourable e-RA output in terms of financial savings, it was analysed to what extent the condition of minimal participation of four bidders is satisfied, as recommended in [21]. In order to test for the association between the different types of contract and the fulfilment of more than three bidders, we conducted a chi-square test and we obtained the results in Table 4.

The $\chi^{2}$ test of independence takes value 8.783 under 3 degrees of freedom $\chi^{2}$ distribution, what means a $p$ value of
0.032. So, under a 0.05 level of significance, we proved that there is an association among these two variables, because differences in distribution are enough to reject the null hypothesis on the independence of the examined categorical variables. This conclusion is also graphically supported by the conditional bar chart plotted in Figure 2(a).

In a complementary manner, a histogram depicting the detailed distribution of the number of bidders in tenders in the BUI, COM, OTH, and PRM categories is shown in Figure 2(b). It is clearly visible that, for the OTH and PRM categories, almost half of the examined tenders reported 3 bidders as maximum, which is slightly below the recommended limit. The maximum reported number of bidders for these categories was only 6 . In contrast to this, both BUI and COM categories reported tenders with more than 6 bidders, while on the contrary, a considerable amount of tenders in the BUI category (12.9\%) reported a single bidder. This represents a very unfavourable situation because the element of competition is not present at all. Furthermore, it can be expected that, in e-RA, many contractors will initially submit a higher bid price in order to create space for further bid price reduction during the comparison round. As a consequence, it may happen that the award price achieved through e-RA will be higher compared to traditional procurement when only one bid is submitted.

\subsection{Analysis of Relationships between e-RA Variables.} Relationships between selected e-RA variables were examined by using matricial scatterplots and correlation analysis. These variables contain the following: the number of bidders (NOB), best bid before auction (BBA), number of changes of bids during comparison round (CHA), and the amount of achieved relative savings (ARSs). The variables $\mathrm{NOB}$ and $\mathrm{CHA}$ indicate competition in the auction; BBA represents the attractiveness of the contract in terms of its financial volume, and ARS indicates the most important auction outcome.

In order to explore the potential relationships between each pair of variables, without fitting a specific model-such as a regression line or a theoretical distribution-and to reduce the impact of influencing observations, we plotted the data together with the locally weighted scatterplot smoother-from here on lowess-Cleveland [60] profile. The resulting graphs are depicted in Figure 3. Despite the smoothing strategy, we can observe the impact of the outliers in the resulting estimated lowess profiles (in particular when the output variable is the achieved amount of savings) and that a clear shape for the estimation model does not exist. 
When estimating Pearson's correlation coefficient matrices for the variables NOB, BBA, CHA, and ARS according to Evans [61], denoted by $R$ for the global dataset and BUI, $\mathrm{COM}, \mathrm{OTH}$, and PRM when we stratify within the different types of contract, we obtained the following results:

$$
\begin{aligned}
& R=\left(\begin{array}{cccc}
1 & 0.042 & 0.225^{*} & 0.262^{*} \\
0.042 & 1 & -0.003 & -0.073 \\
0.225^{*} & -0.003 & 1 & 0.232^{*} \\
0.262^{*} & -0.073 & 0.232^{*} & 1
\end{array}\right), \\
& R_{\mathrm{BUI}}=\left(\begin{array}{cccc}
1 & 0.124 & 0.240^{*} & 0.291^{*} \\
0.124 & 1 & 0.073 & 0.066 \\
0.240^{*} & 0.073 & 1 & 0.471^{*} \\
0.291^{*} & 0.066 & 0.471^{*} & 1
\end{array}\right) \text {, } \\
& R_{\mathrm{COM}}=\left(\begin{array}{cccc}
1 & 0.070 & 0.262 & 0.526^{*} \\
0.070 & 1 & -0.015 & -0.064 \\
0.262 & -0.015 & 1 & 0.186 \\
0.526^{*} & -0.064 & 0.186 & 1
\end{array}\right) \text {, } \\
& R_{\mathrm{OTH}}=\left(\begin{array}{cccc}
1 & -0.137 & 0.259 & -0.164 \\
-0.137 & 1 & -0.199 & -0.178 \\
0.259 & -0.199 & 1 & 0.159 \\
-0.164 & -0.178 & 0.159 & 1
\end{array}\right) \text {, } \\
& R_{\mathrm{PRM}}=\left(\begin{array}{cccc}
1 & -0.073 & 0.426^{*} & 0.295 \\
-0.073 & 1 & -0.070 & -0.093 \\
0.426^{*} & -0.070 & 1 & 0.284 \\
0.295 & -0.093 & 0.284 & 1
\end{array}\right) \text {, }
\end{aligned}
$$

where values with ${ }^{*}$ denote a linear correlation coefficient statistically different from 0 at $\alpha=0.05$ significance level.

The results reveal just weak ( $r$ in $0.20-0.39$ ) positive correlations for the global dataset: NOB-CHA, NOB-ARS, and CHA-ARS. At this level, therefore, it is not possible to speak about important relationships between variables. However, when looking at stratified data according to the TOC, more interesting relationships are emerging. For BUI, there is moderate positive correlation (0.471) between $\mathrm{CHA}$ and ARS. For COM, the strongest relation exists between NOB and ARS (0.526). For OTH, just weak or very weak correlations were identified, and in PRM category, one moderate correlation (0.426) between NOB and CHA has been detected.

These results suggest that the market conditions and bidding strategy may differ according to TOC. For BUI, the results indicate that higher ARS is associated with strong competition even with fewer numbers of bidders, while for COM, the amount of ARS is more dependent on NOB, i.e., it is less likely to expect higher savings with a lower number of bidders. In the case of PRM, higher amount of CHA can be achieved if the buyer is able to attract more bidders to the auction. We attribute the appearance of just weak or very weak relations in OTH to the great variety of tenders with respect to their character. As no important relationship of
BBA with any other variable was detected, this suggests that the attractiveness of the contract cannot be considered a factor contributing to higher competition in e-RA. From this, we can infer that small-scale contracts will not be more frequently followed by the problem of participation of suppliers.

4.6. Evaluation of Achieved Savings. From the previous section we knew that, in order to predict the achieved relative savings (ARSs), the main predictor variables are the number of bidders (NOB) and the number of changes during the auction (CHA). However, the variables NOB and $\mathrm{CHA}$ are also correlated, and it could happen that part of the variability in ARS may be explained simultaneously by both with also a potential effect of the interaction between both variables. Based on this and to control for colinearity, we estimated the best model for ARS in the family of linear models with the covariates $\mathrm{NOB}$ and $\mathrm{CHA}$ and its interaction NOB-CHA, that is,

$$
\mathrm{ARS}=\beta_{0}+\beta_{1} \cdot \mathrm{NOB}+\beta_{2} \cdot \mathrm{CHA}+\beta_{3} \cdot \mathrm{NOB} \cdot \mathrm{CHA}+\varepsilon,
$$

where the error term follows a zero-mean normal distribution, i.e., $\varepsilon \sim N\left(0, \sigma^{2}\right)$.

When estimating the model in the overall dataset and the different categories in TOC, we realized that, in categories $\mathrm{OTH}$ and PRM, neither variables NOB and CHA nor its interaction is significant (at $\alpha=0.05$ ). This result was consistent with the correlation matrices in those groups. A summary of the most significant regression models at a $95 \%$ confidence level is reported in Table 5. The final criterion for accepting the model was a significant improvement of the $R^{2}$-adjusted coefficient after considering the complexity of the resulting linear model.

From models in Table 5, we can derive that the most impacting variable on the amount of savings is the number of bidders. The baseline effect of one extrabidder in the percentage of savings can be roughly estimated in 3 units in the overall dataset, 2 units in the BUI contracts and 4 units in the COM contracts. Less impacting is the effect of the number of changes that it can be only moving the percentage of savings in the overall dataset and the BUI subsample. In particular, in these datasets, the baseline benefit is of 1 unit of percentage every 4 changes, which is reduced due to the interaction when the number of bidders and changes increase in about 1 unit every bidder and 25 changes. Note that, in the COM contracts, the covariate number of changes is not significant, which states that the estimation of the amount of saving is only dependent on the number of bidders. The predictions we can estimate with the models in Table 5, as well as the effect of number of changes on the amount of saving as a function of the number of bidders, are displayed in Figure 4 by contour plots and stratified scatterplots for the estimation of the achieved relative savings percentage.

The findings resulting from Figure 4 are very interesting because they highlight the importance of TOC in our analysis. Firstly, it is clearly visible that the contour plots for 


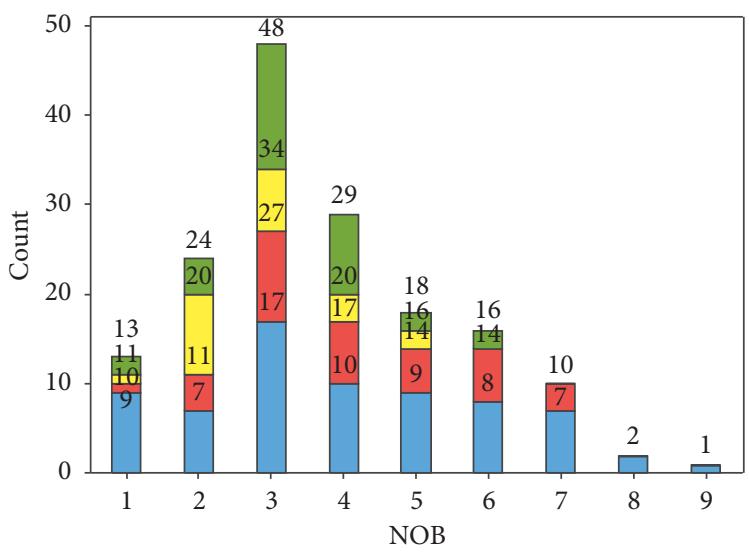

TOC

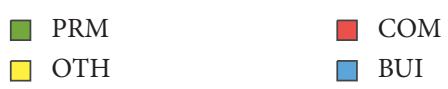

(a)

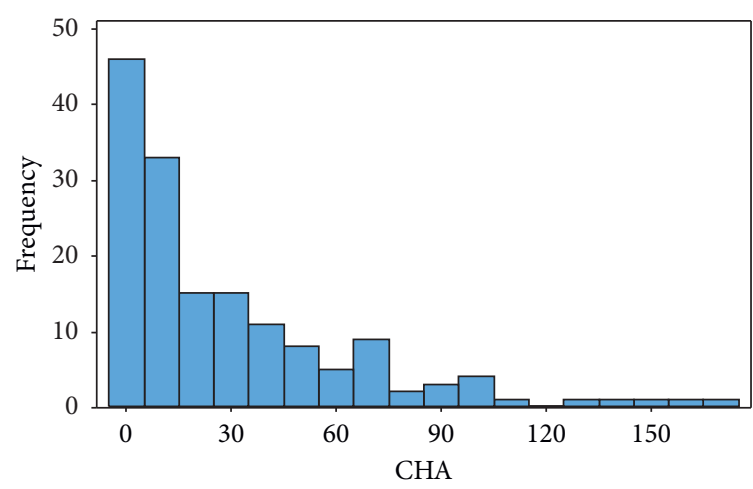

(c)

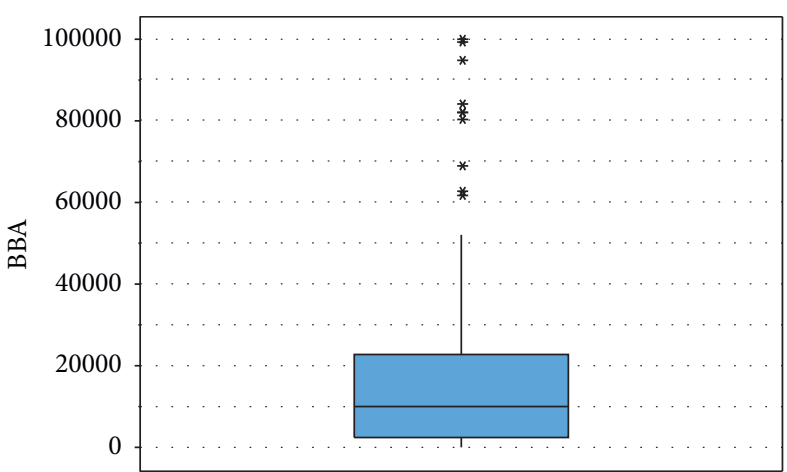

(b)

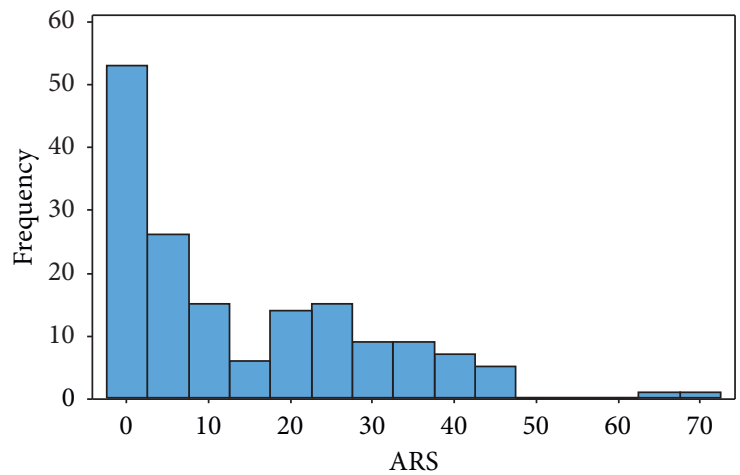

(d)

FIgURE 1: Distributions of the data for the following variables: (a) bar chart of NOB stacked by categories in TOC, (b) boxplot of BBA ${ }^{1}$, (c) histogram of $\mathrm{CHA}^{2}$, and (d) histogram of ARS. ${ }^{1}$ Records with BBA $>100,000(n=8)$ were not depicted. ${ }^{2}$ Records with $\mathrm{CHA}>200(n=4)$ were not depicted.

TABLE 4: Contingency table for the $\chi^{2}$ test among the type of contract and the dichotomized number of bidders for the construction e-RA dataset.

\begin{tabular}{lcclll}
\hline TOC & $\begin{array}{c}\text { NOB } \leq 3 \\
\text { Frequency (row \%) }\end{array}$ & $\begin{array}{c}\text { NOB } \geq 4 \\
\text { Frequency (row \%) }\end{array}$ & $\chi^{2}$ & df & $p$ \\
\hline BUI & $33(47.1)$ & $37(52.9)$ & & & \\
COM & $15(41.7)$ & $21(58.3)$ & & & \\
OTH & $17(77.3)$ & $5(22.7)$ & 8.783 & 3 & 0.032 \\
PRM & $20(60.6)$ & $13(39.4)$ & & & \\
Total & $85(52.8)$ & $76(47.2)$ & & & \\
\hline
\end{tabular}

the ARS prediction for the full dataset (Figure 4(a)), BUI (Figure 4(c)) and COM (Figure 4(e)) subsamples are very different. Also stratified scatterplots (Figures 4(b), 4(e), and $4(\mathrm{f}))$ differ from each other. In the case of the full dataset, data indicate that, with a lower $\mathrm{NOB}(\mathrm{NOB}=2)$, it is very important to have a high value of CHA during e-RA to achieve higher ARS. Therefore, it is important to have in the auction those participants who are very interested in getting the contract. In contrast to this, with higher $\mathrm{NOB}(\mathrm{NOB}=8)$, the increasing value of $\mathrm{CHA}$ does not contribute to higher
ARS achievement. In the case of the BUI subsample, the scatterplot suggests that the lower the value of NOB is, the more important the active competition of bidders in e-RA is from the perspective of achieving higher ARS. Especially the COM subsample shows a totally different contour plot and scatterplot for ARS prediction. Data indicate that the CHA variable is not important at all, as the value of ARS depends almost solely on NOB. We attribute this to the fact that a high value of $\mathrm{CHA}$ in this case probably corresponds just to very low relative bid reductions, and therefore, it is very important for the buyer to ensure high participation of bidders.

4.7. Evaluation Method Used in e-RA. Because the studies on Czech and Polish construction tenders reported that the overwhelming majority of them were evaluated solely on the basis of the lowest bid price, it could be expected that the situation is similar in Slovakia. As can be seen in Table 6, regardless of the type of the contract, the overwhelming majority of tenders were evaluated solely on the basis of the lowest bid price. A $\chi^{2}$ test is not sufficient to show if the 


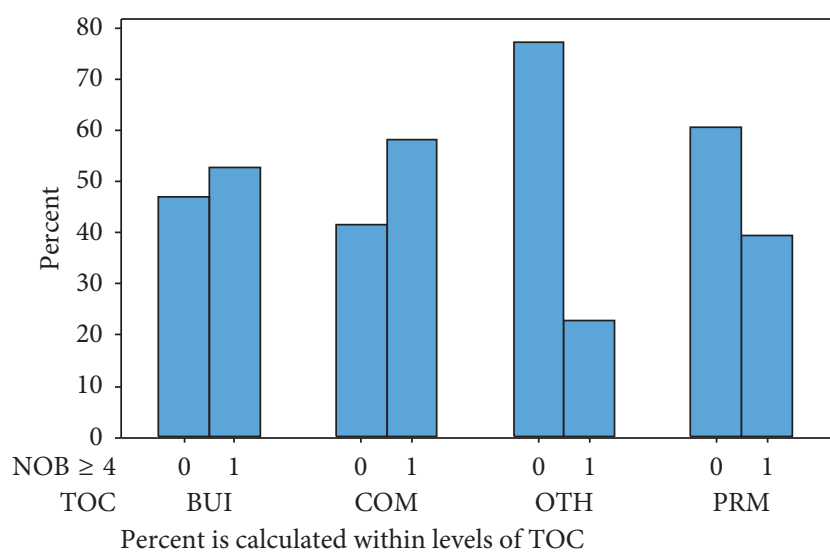

Percent is calculated within levels of TOC

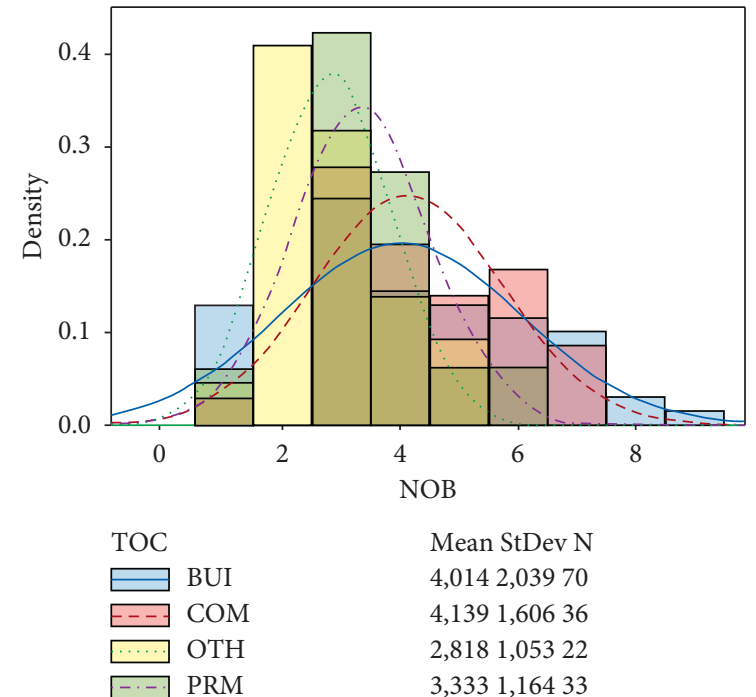

(b)

Figure 2: Descriptive plots for the construction e-RA dataset. (a) Bar chart for the conditional distribution of at least 4 bidders indicator variable given the types of contract variable. (b) Histogram and normal fit for the number of bidders in each type of contract.

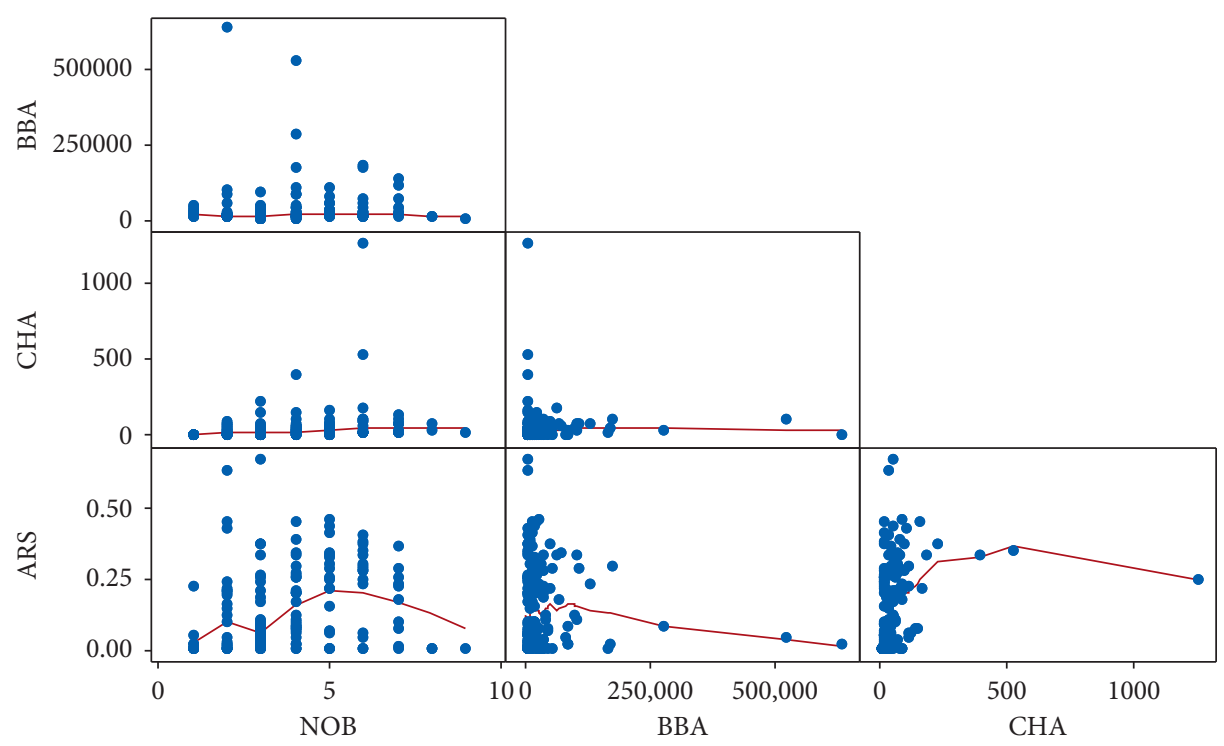

FIgure 3: Matrix plots with lowess smoother for the NOB, BBA, CHA, and ARS variables in the construction e-RA dataset.

TABLE 5: Estimated linear models for the prediction of the achieved relative savings percentage based on the number of bidders, the number of changes, and its interaction, for the full construction e-RA auctions dataset and the BUI and COM types of contract subsets. The models have been chosen at a $\alpha=0.05$ global significance level.

\begin{tabular}{|c|c|c|c|c|c|c|}
\hline \multirow{2}{*}{ Variable } & \multicolumn{2}{|c|}{ Overall sample } & \multicolumn{2}{|c|}{ BUI subsample } & \multicolumn{2}{|c|}{ COM subsample } \\
\hline & Estimate (s.e.) & $p$ value & Estimate (s.e.) & $p$ value & Estimate (s.e.) & $p$ value \\
\hline Intercept & $1.21(2.84)$ & 0.670 & $2.39(3.51)$ & 0.498 & $-5.23(5.38)$ & 0.338 \\
\hline NOB & $2.71(0.67)$ & $<0.001$ & $1.96(0.86)$ & 0.026 & $4.38(1.21)$ & 0.001 \\
\hline $\mathrm{CHA}$ & $0.25(0.06)$ & $<0.001$ & $0.24(0.10)$ & 0.016 & - & - \\
\hline NOB.CHA & $-0.04(0.01)$ & $<0.001$ & $-0.03(0.02)$ & 0.142 & - & - \\
\hline$R^{2}$ & \multicolumn{2}{|c|}{$17.38 \%$} & \multicolumn{2}{|c|}{$27.95 \%$} & \multicolumn{2}{|c|}{$27.71 \%$} \\
\hline
\end{tabular}




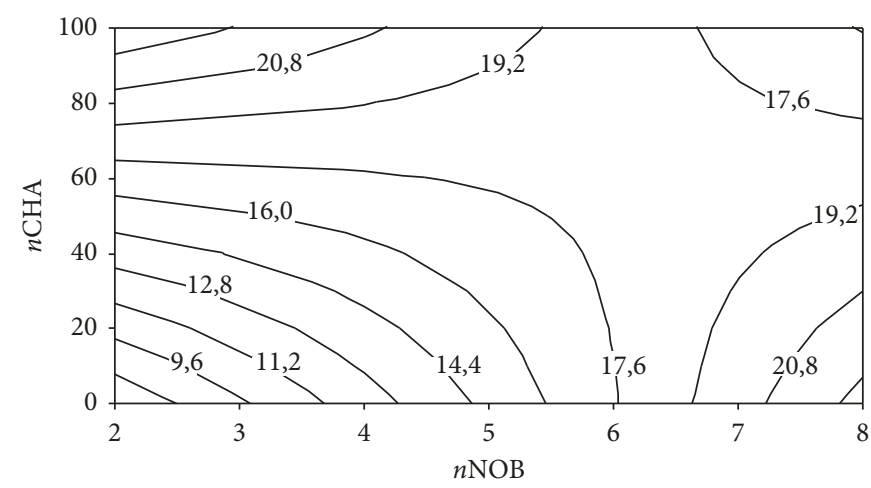

Estimation based on the full dataset

(a)

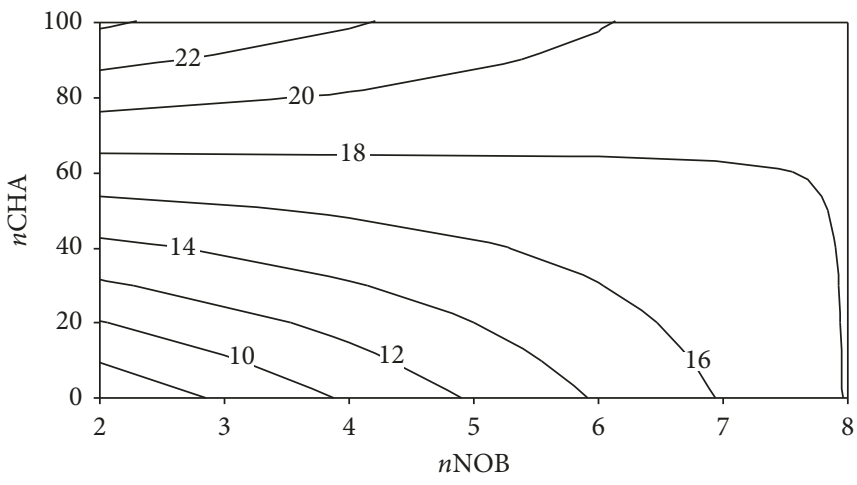

Estimation based on the BUI type of contract

(c)

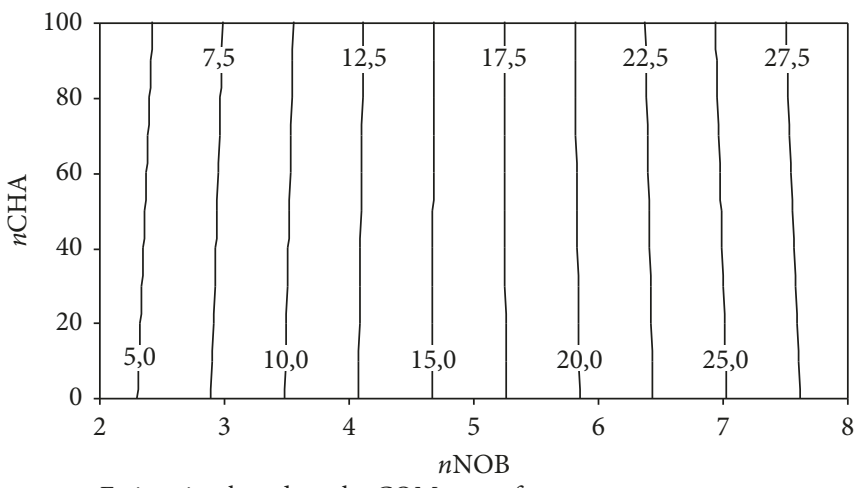

Estimation based on the COM type of contract

(e)
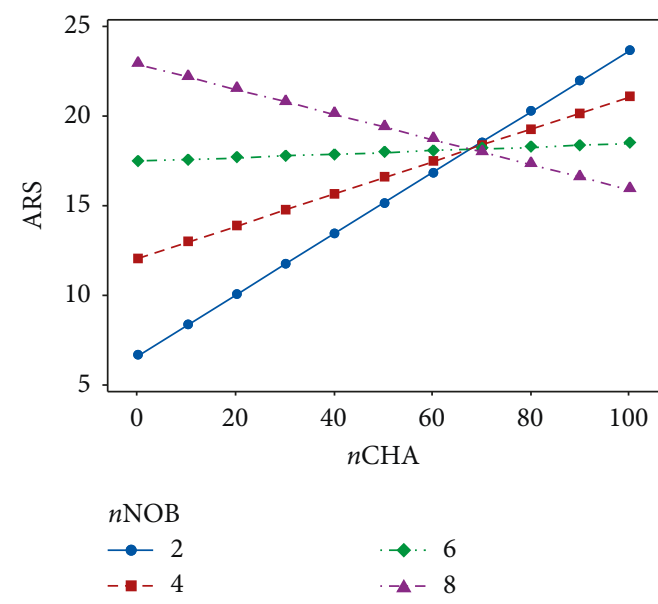

(b)

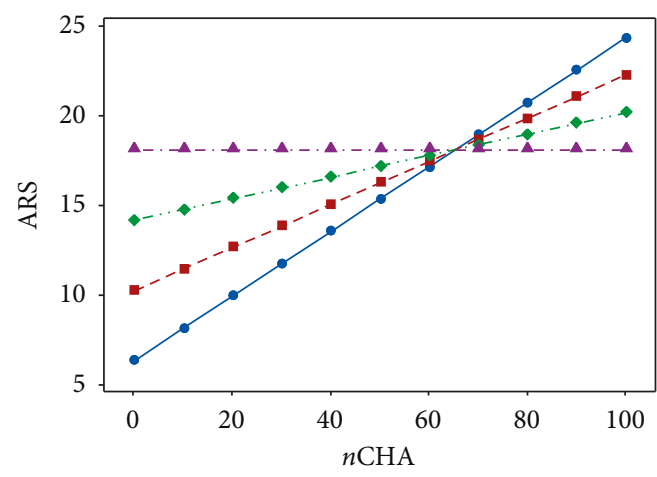

$n \mathrm{NOB}$

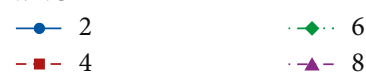

(d)

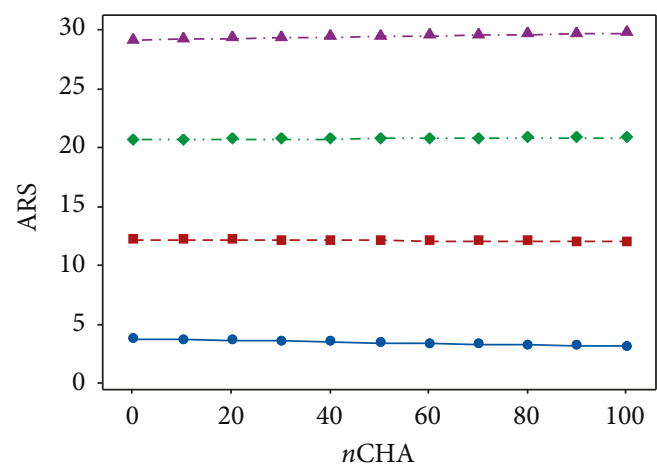

$n \mathrm{NOB}$

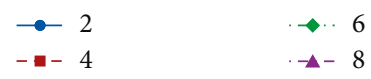

(f)

Figure 4: $(a, c, e)$ Contour plots and $(b, d, f)$ stratified scatterplots for the estimation of the achieved relative savings percentage based on the number of bidders, the number of changes, and its interaction, for the full construction e-RA auctions dataset and the BUI and COM types of contract subsets.

evaluation method used is dependent on the type of the contract, in particular because the expected frequency is lower than 5 in some cells of the contingency table. However, statistics like Cramer's $\left(V^{2}=0.070\right)$ and
Goodman-Kruskal's lambda statistic $\left(\lambda_{\mathrm{TOC}}=0.044 ; \lambda_{\mathrm{TEM}}<\right.$ 0.001 ) prove that there is no a significant association between these two nominal variables or, in other terms, the association seems to be weak. 
TABLE 6: Contingency table for the evaluation method used in e-RA auctions stratified by the type of contracts.

\begin{tabular}{lcc}
\hline Evaluation method & Lowest bid price (\%) & Multicriteria (\%) \\
\hline BUI & $69(98.6)$ & $1(1.4)$ \\
COM & $33(91.7)$ & $3(8.3)$ \\
OTH & $17(77.3)$ & $5(22.7)$ \\
PRM & $30(90.9)$ & $3(9.1)$ \\
Total & $149(92.5)$ & $12(7.5)$ \\
\hline
\end{tabular}

From a global perspective point of view, it has been verified that the Slovak practice in evaluating public tenders from the perspective of the use of lowest bid price is similar to that of the Czech Republic and Poland [44]. This can be attributed to the fact that public authorities prefer simple evaluation on the basis of the lowest bid price in order to avoid potential objections of bidders claiming improperly selected or nonobjective criteria. Specifically, based on the data, the estimated proportion of e-RA auction using the lowest bid price as an evaluation method is $92.5 \%$ (95\% CI: $(87.3 \%, 96.1 \%))$.

4.8. Main Findings and Discussion. The results presented in this paper have shown that a significant proportion of e-RA $(52.8 \%)$ faces low number bidders $(\mathrm{NOB} \leq 3)$. This problem is more distinct for OTH and PRM subsamples (77.3\% and $60.6 \%$, respectively), and the $\chi^{2}$ test of independence proved that there is the statistically significant association among TOC and NOB variables. The effect of TOC has also been revealed by the matricial scatterplots and the correlation analysis of e-RA variables. While positive moderate correlation exists between NOB and ARS in the COM subsample, then positive moderate correlation between CHA and ARS has been identified in the BUI subsample.

Based on the performed analysis, it can be stated that linear models for the prediction of the ARS percentage based on NOB, CHA, and their interaction, as well as subsequent analysis using contour plots and stratified scatterplots, have shown different relationships between the variables examined among the full dataset and individual subsets (BUI and $\mathrm{COM})$.

The results show that the diversity of construction tender types (transport infrastructure projects, buildings, maintenance, etc.) may have significant effect on e-RA outputs. This can be documented in relation to the recommendation of having at least four bidders in the auction [21]. The achieved results therefore coincide with the literature analysis, as similar differences in competition among different types of contracts are corroborated in a similar manner than in [62] for instance.

The results have also highlighted that ARS estimation mainly depends on the NOB. It is therefore crucial for buyers to ensure the sufficient level of competition in e-RA. Data indicated that some types of tenders face the problem of low number of bidders or even insufficient number of bidders (with $\mathrm{NOB}=1$ ). Based on these findings, the need for expost analysis of completed e-RA data arises. Ex-post analysis should focus on variables that have been the subject of interest of this research and that can help us to understand the bidding strategy and willingness of suppliers to participate in tenders. In particular, these variables cover CHA for each bid made in e-RA, the difference between the initial bid and the final bid for each bidder and their possible relation to TOC and attractiveness of the contract that can be measured in terms of BBA. Unfortunately, such detailed data assigned to individual bidders were not at disposal for this stage of research.

Buyers should investigate, which suppliers are highly competitive, what kinds of TOC are attractive for them and also how the high contract value is appealing to each of them. These findings support the suggestion of Tkáč et al. to pay attention to the volume of contract as it is the most significant reason why construction companies decline to bid [29]. Estimating investment costs is the first and crucial cost estimate related to the planned construction activity [63]. Application of e-RA can therefore be encouraged in such market segments where sufficient competition exists, and there is evidence that contractors are willing to compete with their bids.

The appropriate timing of the tender in relation to the seasonality of works and capacity utilization of construction companies may be a significant driver for achieving positive e-RA outcomes. The target number should be adequately stratified according to the different types of tenders; as for the BUI subset, it is more crucial to invite especially highly interested bidders rather than to focus just on high number of bidders. Figure 4 also indicates that the effort to achieve a higher number of bidders is justified for the COM subset. In this case, data suggest that the higher the number of bidders in e-RA, the greater the achieved savings that can be reasonably expected. As no strong association of BBA and other variables has been detected, there is no need to search for a suitable minimum threshold of financial volume of tenders to be sufficiently attractive for contractors.

Finally, the Slovak practice has shown that public authorities mostly prefer the lowest bid price despite the fact that e-RA supports multicriteria evaluation of bids. The focus on financial savings seems to be logical if other tender parameters are fixed and not subject to bid evaluation (such as quality, duration of warranty, and duration of works). However, it is economically justified to use multicriteria in many cases, so public authorities should consider changing their approach and paying more attention not just to lifecycle costs but also to other aspects such as limitation of the use of detour routes during roadworks. The need to change the approach to multicriteria evaluation also comes from the Directive 2014/24/EU on public procurement [9], supports achieving objectives of sustainability in public procurement (performance criteria should be linked to the life cycle and the sustainability of the production process of works).

The studied area (Slovakia) belongs together with other three Central European States (the Czech Republic, Hungary, and Poland) to the Visegrád Group (V4). Taking into consideration that V4 countries have undergone the same process since 1989 (democratic establishment, economic transformation, and accession to the European Union), findings presented in this paper are valuable for purchasing 
practitioners within the whole V4 area. Moreover, the international impact of this research also covers other Central European countries (e.g., Slovenia) and Southeast European countries (e.g., Croatia) that have undergone the similar process as V4 and that have adopted the option of e-RA use within public procurement.

\section{Conclusions and Research Implications}

This paper has addressed the use of e-RA in relation to construction tenders in Slovakia by performing an empirical analysis of real auction data. More specifically, the issues concerning competition in auctions and preferred evaluation method were examined; predictive variables and the corresponding statistical model for the amount of relative saving were selected. The findings presented in this paper aim to contribute to a more informed decision on e-RA application in procurement practice relating to the construction sector and result in both theoretical and managerial implications.

From the theoretical perspective, this research contributes to the limited body of knowledge in the area of construction auctions by providing detailed empirical insight of the real data on completed public tenders. In particular, this paper extends the literature by examining relationships of selected e-RA variables with the motivation to contribute to the better understanding of the construction e-RA's nature and buyers' expectations relating to the potential financial benefit of the e-RA use. These theoretical findings can be applied within the theory of IT adoption, e.g., when examining technology acceptance model [64] for the purpose of construction auctions adoption.

The findings presented in the previous sections have also revealed several remarkable managerial implications in the area of construction procurement. The ability to approximately evaluate the potential of ARS is important as this might be another important factor for purchasing managers regarding the decision to adopt e-RA, as the use of e-RA is not free of charge. The data presented in this paper may also help us to provide improved prediction of investment costs with regard to the potential savings achieved from the expected value of the contract. From this point of view, more accurate estimation of achievable savings through e-RA could support investors' decision-making.

5.1. Limitations of the Paper and Future Research Considerations. This research is not without its limitations. Firstly, the size of the sample did not allow a separate correlation analysis for individual subject types of tenders. If this was possible, the results would certainly contribute to a deeper understanding of the effects of this categorical variable on e-RA variables. Secondly, the examination of the evaluation method used in e-RA has also been limited due to missing data on evaluation criteria other than price and their weights. However, with regard to the percentage of the multicriteria evaluation in the sample, these data will not be significant from a statistical perspective and thus will have only an indicative value. And thirdly, the data presented in this paper refer to the Slovak practice. It can be expected that, in other countries, the relationship between the same variables could be of a different nature or strength. Future comparative studies on the topic of e-RA in the construction sector may bring further interesting insights on a transnational scale.

Future research should focus on a more detailed analysis of e-RA variables from the perspective of the type of the tender. More specifically, it would be desirable to use a greater number of data to determine the recommended minimum number of bidders for individual types of contracts, such as buildings, transportation, maintenance of roads, maintenance of facilities, and construction project services, or other services related to construction. Furthermore, such analysis should also take into account the fluctuations in economic activity over the business cycle.

Another direction of further research may also examine the attractiveness of tenders in terms of their financial volume. Together with the type of the tender, the expected volume of the tender also plays an important role because with a higher expected value, a tender becomes more attractive for prospective contractors. Accordingly, the establishment of the threshold below which e-RA tenders are not attractive for suppliers anymore would also be beneficial for construction procurement practice.

As this research does not address postauction data, further research should also focus on cost overruns after the execution of construction works based on the final invoice.

\section{Data Availability}

The data (e-RA records) used to support the findings of this study have not been made available because of the agreement with the e-RA system operator.

\section{Conflicts of Interest}

The authors declare that they have no conflicts of interest.

\section{Acknowledgments}

This paper has been worked out under the project No. LO1408 AdMaS UP-Advanced Materials, Structures and Technologies-and supported by the Ministry of Education, Youth and Sports under the National Sustainability Programme I of the Czech Republic, and it has been also partially supported by grants MTM2015-64465-C2-1-R (MINECO/FEDER) from the Ministerio de Economía $y$ Competitividad (Spain) and 2017 SGR 622 from the Departament d'Economia i Coneixement de la Generalitat de Catalunya, and the SmartTransLog Erasmus+ Consorcium (2016-1-ES01-KA108-023465).

\section{References}

[1] A. Travaglini, M. Radujkovic, and M. Mancini, "Building information modelling (BIM) and project management: a stakeholders perspective," Organization, Technology and Management in Construction: An International Journal, vol. 6, no. 2, pp. 1001-1008, 2014. 
[2] J. Mbachu and R. Nkado, "Conceptual framework for assessment of client needs and satisfaction in the building development process," Construction Management and Economics, vol. 24, no. 1, pp. 31-44, 2006.

[3] Y. J. Zidane, A. Johansen, and A. Ekambaram, "Project evaluation holistic framework-application on megaproject case," Procedia Computer Science, vol. 64, pp. 409-416, 2015.

[4] Ž. Ljevo and M. Vukomanović, "Project management practiced in public project stream of Bosnia and Herzegovina," Procedia-Social and Behavioral Sciences, vol. 119, pp. 692-701, 2014.

[5] V. Žujo, D. Car-Pušic, and A. Brkan-Vejzović, "Contracted price overrun as contracted construction time overrun function," Tehnicki Vjesnik, vol. 17, no. 1, pp. 23-29, 2010.

[6] A. Czarnigowska and A. Sobotka, "Time-cost relationship for predicting construction duration," Archives of Civil and Mechanical Engineering, vol. 13, no. 4, pp. 518-526, 2013.

[7] B. Dimitrov and V. Žileska-Pančovska, "Structure of price elements for construction works on water engineering systems," Gradjevinar, vol. 67, no. 4, pp. 363-368, 2015.

[8] F. Tazelaar and C. Snijders, "Dispute resolution and litigation in the construction industry. Evidence on conflicts and conflict resolution in The Netherlands and Germany," Journal of Purchasing and Supply Management, vol. 16, no. 4, pp. 221-229, 2010.

[9] Directive 2014/24/EU of the European Parliament and of the Council of 26 February 2014 on public procurement and repealing Directive 2004/18/EC.

[10] N. Jajac, I. Marovic, and M. Mladineo, "Planning support concept to implementation of sustainable parking development projects in ancient Mediterranean cities," Croatian Operational Research Review, vol. 5, no. 2, pp. 345-359, 2014.

[11] M. L. Emiliani and D. J. Stec, "Realized savings from online reverse auctions," Supply Chain Management, vol. 7, no. 1, pp. 12-23, 2002.

[12] M. C. J. Caniëls and E. M. van Raaij, "Do all suppliers dislike electronic reverse auctions?," Journal of Purchasing and Supply Management, vol. 15, no. 1, pp. 12-23, 2009.

[13] T. Hanák, T. Chadima, and J. Šelih, "Implementation of online reverse auctions: comparison of Czech and Slovak construction industry," Engineering Economics, vol. 28, no. 3, pp. 271-279, 2017.

[14] O. Cabral, L. Ferreira, and G. P. Dias, "Adoption of reverse auctions in public e-procurement: The case of Portugal," in Proceedings of Iberian Conference on Information Systems and Technologies (CISTI 2016), Gran Canaria, Spain, July 2016.

[15] S. Muylle and W. Standaert, "The use of procedural fairness in electronic reverse auctions to enhance relationship quality," Psychology and Marketing, vol. 33, no. 4, pp. 283-296, 2016.

[16] R. Delina, "Transparency in electronic business negotiationsevidence based analysis," Quality Innovation Prosperity, vol. 18, no. 2, pp. 79-89, 2014.

[17] M. Kostic, L. Maksimovic, and B. Stojanovic, "The limitations of competition in the insurance markets of Slovenia, Croatia and Serbia," Economic Research-EkonomskaIstraživanja, vol. 29, no. 1, pp. 395-418, 2016.

[18] K. Ye, L. Shen, and W. Lu, "A discriminant model for measuring competition intensity of construction market," Engineering, Construction and Architectural Management, vol. 21, no. 2, pp. 152-169, 2014.

[19] S. Wu and G. E. Kersten, "Procurement auctions and negotiations: an empirical comparison," Journal of Organizational Computing and Electronic Commerce, vol. 27, no. 4, pp. 281-303, 2017.
[20] N. Celentani and J. Ganuza, "Corruption and competition in procurement," European Economic Review, vol. 46, no. 7, pp. 1273-1303, 2002.

[21] S. M. Wagner and A. P. Schwab, "Setting the stage for successful electronic reverse auctions," Journal of Purchasing and Supply Management, vol. 10, no. 1, pp. 11-26, 2004.

[22] M. Schmidt, "Price determination in public procurement: simulation," Politicka ekonomie, vol. 64, no. 5, pp. 541-558, 2016.

[23] M. H. Rothkopf and A. B. Whinston, "On E-auctions for procurement operations," Production and Operations Management, vol. 16, no. 4, pp. 404-408, 2009.

[24] K. Gugler, M. Weichselbaumer, and C. Zulehner, "Competition in the economic crisis: analysis of procurement auctions," European Economic Review, vol. 73, pp. 35-57, 2015.

[25] A. Soo and B. L. Oo, "The effect of construction demand on contract auctions: an experiment," Engineering, Construction and Architectural Management, vol. 21, no. 3, pp. 276-290, 2014.

[26] T. Hanák, "Electronic reverse auctions in public construction procurement -empirical evidence from the Czech Republic," Archives of Civil Engineering, vol. 52, no. 3, pp. 47-60, 2016.

[27] S. Wamuziri, "Using electronic reverse auctions in project procurement: perceptions of construction contractors," in Proceedings of 25th Annual ARCOM Conference, Association of Researchers in Construction Management, pp. 167-176, Cardiff, Wales, September 2009.

[28] B. Zunk, M. Marchner, I. Uitz, C. Lerch, and H. Schiele, "The role of E-procurement in the Austrian construction industry: adoption rate, benefits and barriers," International Journal of Industrial Engineering and Management, vol. 5, no. 1, pp. 13-21, 2014.

[29] M. Tkáč, R. Delina, and M. Sabolová, “Analysis of request for proposals in construction industry," Quality Innovation Prosperity, vol. 20, no. 1, pp. 104-117, 2016.

[30] A. Leśniak and E. Plebankiewicz, "Modeling the decisionmaking process concerning participation in construction bidding," Journal of Management in Engineering, vol. 31, no. 2, article 04014032, 2015.

[31] P. Ballesteros-Pérez, M. Skitmore, E. Pellicer, and J. H. Gutiérrez-Bahamondes, "Improving the estimation of probability of bidder participation in procurement auctions," International Journal of Project Management, vol. 34, no. 2, pp. 158-172, 2016.

[32] P. L. Conti, L. De Giovanni, and M. Naldi, "A rank-andcompare algorithm to detect abnormally low bids in procurement auctions," Electronic Commerce Research and Applications, vol. 11, no. 2, pp. 192-203, 2012.

[33] M. O. Ahmed, I. H. El-Adaway, K. T. Coatney, and M. S. Eid, "Construction bidding and the winner's curse: game theory approach," Journal of Construction Engineering and Management, vol. 142, no. 2, article 04015076, 2016.

[34] A. Megremis, "Abnormally low tenders: making detection objective," The International Construction Law Review, vol. 31, no. 4, pp. 460-478, 2014.

[35] P. Ballesteros-Pérez, M. Skitmore, E. Pellicer, and M. C. González-Cruz, "Scoring rules and abnormally low bids criteria in construction tenders: a taxonomic review," Construction Management and Economics, vol. 33, no. 4, pp. 259-278, 2015.

[36] P. Ballesteros-Pérez, M. Skitmore, R. Das, and M. L. Del Campo-Hitschfeld, "Quick abnormal-bid-detection method for construction contract auctions," Journal of Construction 
Engineering and Management, vol. 141, no. 7, article 04015010, 2015.

[37] P. R. Chowdhury, "Controlling collusion in auctions: the role of ceilings and reserve prices," Economic Letters, vol. 98, no. 3, pp. 240-246, 2008.

[38] C. R. Carter, L. Kaufmann, S. Beall, P. L. Carter, T. E. Hendrick, and K. J. Petersen, "Reverse auctionsgrounded theory from the buyer and supplier perspective," Transportation Research Part E: Logistics and Transportation Review, vol. 40, no. 3, pp. 229-254, 2004.

[39] T. I. Tunca, D. J. Wu, and F. V. Zhong, "An empirical analysis of price, quality, and incumbency in procurement auctions," Manufacturing and Service Operations Management, vol. 16, no. 3, pp. 346-364, 2014.

[40] P. E. D. Love and H. Li, "Quantifying the causes and costs of rework in construction," Construction Management and Economics, vol. 18, no. 4, pp. 479-490, 2000.

[41] Y. Jin, J. K. Ryan, and W. Yund, "Two stage procurement processes with competitive suppliers and uncertain supplier quality," IEEE Transactions on Engineering Management, vol. 61, no. 1, pp. 147-158, 2014.

[42] A. Srdic and J. Selih, "Delays in construction projects: causes and mitigation," Organization, Technology and Management in Construction: An International Journal, vol. 7, no. 3, pp. 1383-1389, 2015.

[43] S. Laryea, "Quality of tender documents: case studies from the UK," Construction Management and Economics, vol. 29, no. 3, pp. 275-286, 2011.

[44] T. Hanák, J. Korytárová, R. Kozik, and E. RadziszewskaZielina, "Exploration of contractor evaluation process in the management of public works contracts," in Project Management As a Spectrum of Scientific Problems in Engineering and Management, pp. 55-65, WSOWL, Wroclav, Poland, 2015.

[45] R. SchneiderovaHeralova, "Life cycle costing in the preparation of public works contracts," in Proceedings of International Scientific Conference on People, Buildings and Environment 2014, vol. 4, pp. 394-404, Kroměříž, Czech Republic, 2014.

[46] J. Korytárová and B. Pospíšilová, "Evaluation of investment risks in CBA with Monte Carlo method," Acta Universitatis Agriculturae et Silviculturae Mendelianae Brunensis, vol. 63, no. 1, pp. 245-251, 2015.

[47] K. Parikka-Alhola and A. Nissinen, "Environmental impacts of transport as award criteria in public road construction procurement," International Journal of Construction Management, vol. 12, no. 2, pp. 35-49, 2012.

[48] G. Lewis and P. Bajari, "Procurement contracting with time incentives: theory and evidence," Quarterly Journal of Economics, vol. 126, no. 3, pp. 1173-1211, 2011.

[49] P. Odehnalova, L. Komarkova, and P. Pirozek, "The association of selected economic parameters in construction output-an international comparison," Economic ResearchEkonomska Istraživanja, vol. 29, no. 1, pp. 18-31, 2016.

[50] T. Hanák, "Electronic reverse auctions in public sector construction procurement: case study of Czech buyers and suppliers," TEM Journal, vol. 7, no. 1, pp. 41-52, 2018.

[51] Y. Wang, X. Wang, J. Wang, P. Yung, and G. Jun, "Engagement of facilities management in design stage through BIM: framework and a case study," Advances in Civil Engineering, vol. 2013, Article ID 189105, 8 pages, 2013.

[52] CEEC Research, CEER Research, Kvartálna analýza slovenského stavebníctva Q3/2017 (Title in English: Quarterly
Analysis of the Slovak Construction), Průhonice, Czech Republic, January 2018, , http://www.ceec.eu/research/.

[53] Statistical Office of the Slovak Republic, Yearbook of Construction in SR 2017, Statistical Office of the Slovak Republic, Slovakia, January 2018, https://slovak.statistics.sk.

[54] Statistical Office of the Slovak Republic, Official Website, January 2018, https://slovak.statistics.sk.

[55] E. Sičáková-Beblavá, S. Šatníková, and P. Klátik, "Elektronické aukcie vo verejnom obstarávani: teória a prax na Slovensku" (Title in English: electronic Auctions in Public Procurement: Theory and Practice in Slovakia), Transparency International Slovensko, Bratislava, Slovakia, August 2016, http://www. transparency.sk/wp-content/uploads/2010/01/aukcie.vnutro. indd_.pdf.

[56] Office for Public Procurement, Výkladové stanovisko $k \$ 43$ zákona o verejnom obstarávanî" (Title in English: Explanatory opinion to $\$ 43$ of the Law on Public Procurement), August 2016, https://www.uvo.gov.sk/vykladove-stanoviska/-/asset_ publisher/7gWP3f2ikLHv/content/vykladove-stanovisko-k\%C2\%A7-43-zakona-o-verejnom-obstaravani.

[57] Slovak Republic, Zákon o verejnom obstarávaní č. 25/2006 Z. z. (Title in English: Act no. 25/2006 Coll., o Public Procurement), https://www.uvo.gov.sk/vdoc/1008/zakon-overejnom-obstaravani-c252006-zz-14.html.

[58] Minitab Inc., Minitab ${ }^{\circledR}$, Minitab Inc., USA, 2017, http://www. minitab.com.

[59] D. C. Montgomery and G. C. Runger, Applied Statistics and Probability for Engineers, ISBN 978-0-470-05304-1, John Wiley \& Sons, Inc., Hoboken, NJ, USA, 5th edition, 2010.

[60] W. S. Cleveland, "Robust locally weighted regression and smoothing scatterplots," Journal of the American Statistical Association, vol. 74, no. 368, pp. 829-836, 1979.

[61] J. D. Evans, Straightforward Statistics for the Behavioural Sciences, Brooks/Cole Publishing, Pacific Grove, CA, USA, 1996.

[62] J. Ćetković, M. Knežević, M. Žarković, V. Murgul, and N. Vatin, "Development and competitiveness improvement of the construction sector in Montenegro," Applied Mechanics and Materials, vol. 638-640, pp. 2465-2470, 2014.

[63] E. Plebankiewicz, A. Leśniak, V. Hromádka, E. Vítková, and G. Kocourková, "Estimating the value of public construction works in Poland and the Czech Republic," Scientific Review Engineering and Environmental Sciences, vol. 25, no. 2, pp. 206-219, 2016.

[64] N. Marangunic and A. Granic, "Technology acceptance model: a literature review from 1986 to 2013," Universal Access in the Information Society, vol. 14, no. 1, pp. 81-95, 2015. 


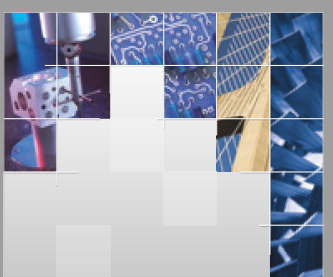

\section{Enfincering}
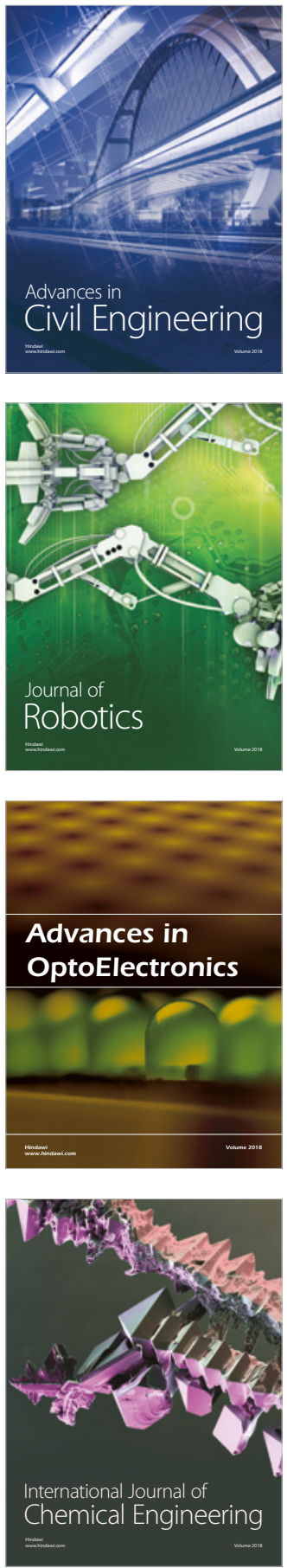

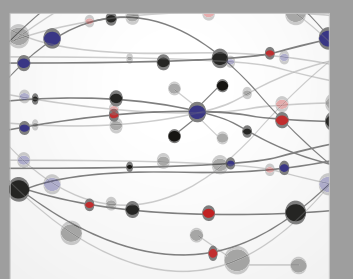

\section{Rotating \\ Machinery}

The Scientific World Journal

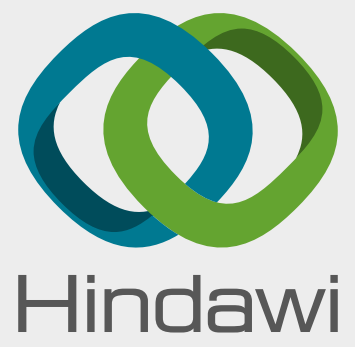

Submit your manuscripts at

www.hindawi.com
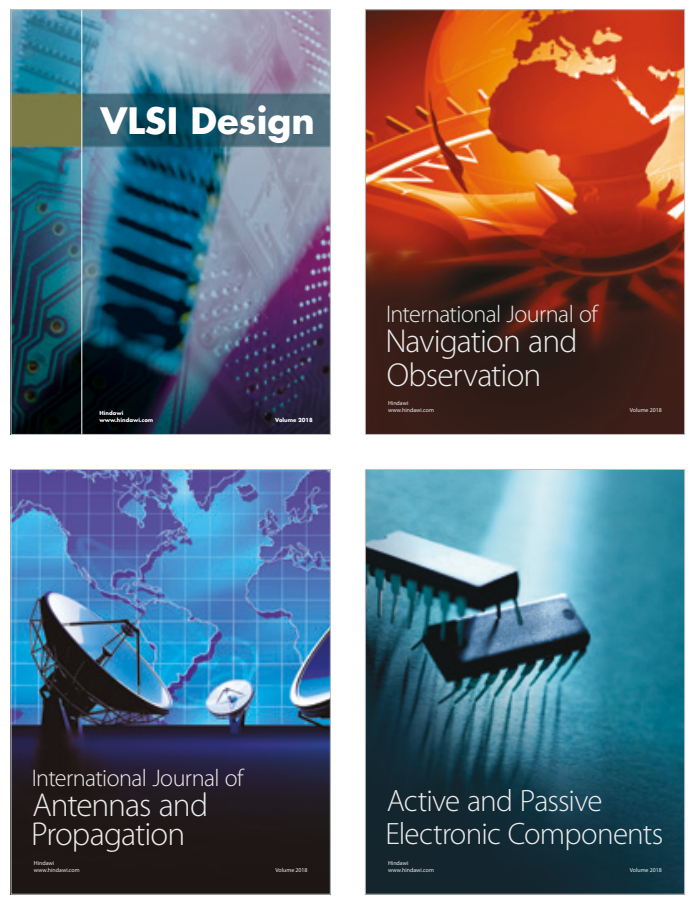
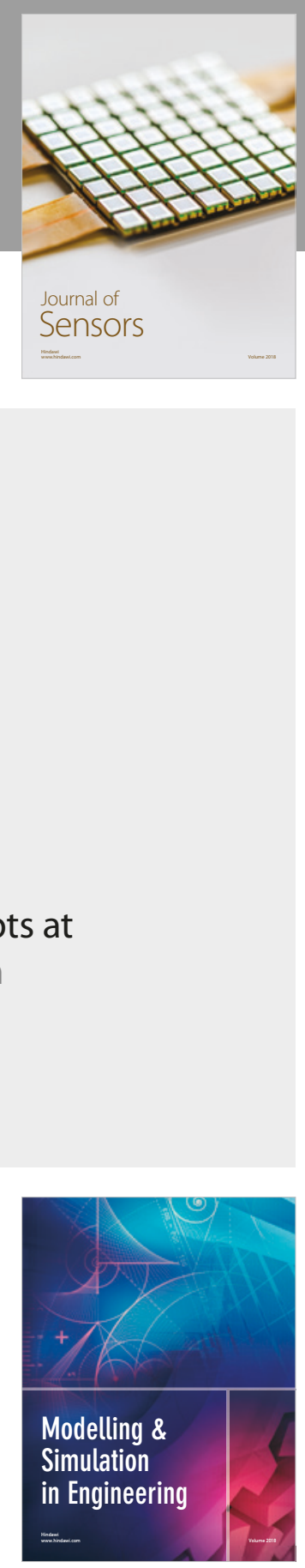

\section{Advances \\ Multimedia}
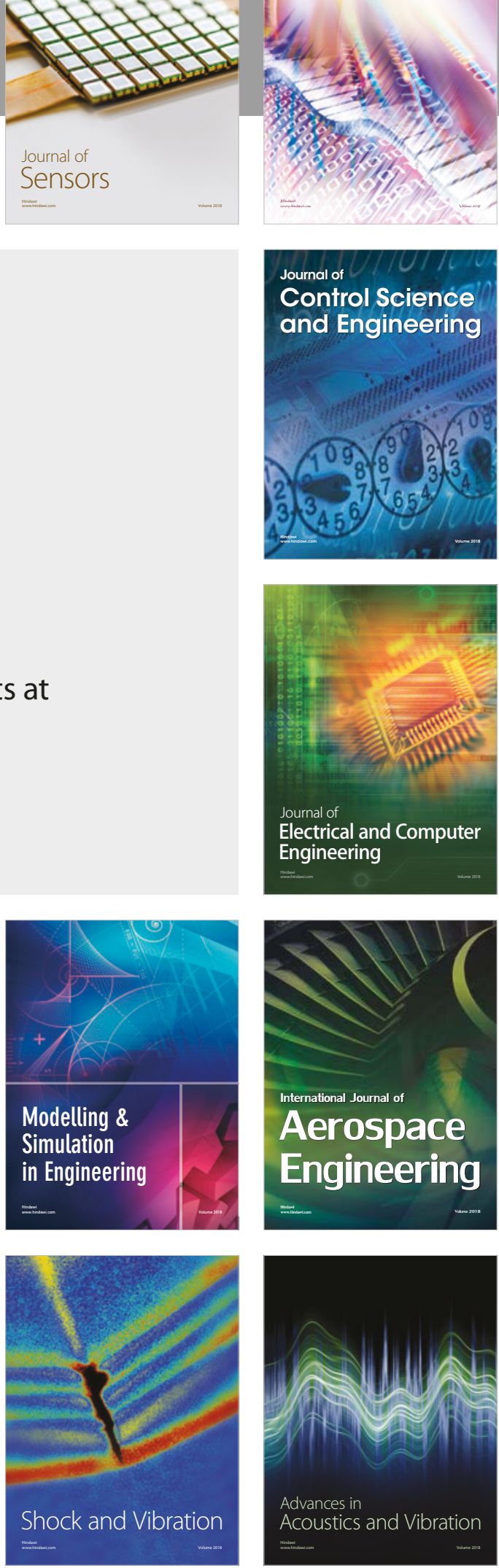